\title{
Identification of Risk Factors for Diabetes Disability among Bangladeshi Adults
}

\author{
K.C.Bhuyan \\ Professor (Retired) of Statistics, Jahangirnagar University, Dhaka, Bangladesh
}

Corresponding Author: K.C.Bhuyan, Professor (Retired) of Statistics, Jahangirnagar University, Dhaka, Bangladesh.

Received Date: 07 October 2021 | Accepted Date: 30 December 2021 | Published Date: 07 January 2022

Citation: K.C.Bhuyan, (2022). Identification of Risk Factors for Diabetes Disability among Bangladeshi Adults. J. Diabetes and Islet Biology, 5(1); DOI: $10.31579 / 2641-8975 / 027$

Copyright: (C) 2022 K.C.Bhuyan, This is an open access article distributed under the Creative Commons Attribution License, which permits unrestricted use, distribution, and reproduction in any medium, provided the original work is properly cited.

\begin{abstract}
The paper was to throw some light on the risk factors for diabetes disability among Bangladeshi adults of 18 years and above residing in both urban and rural areas. In investigating the adults, it was decided to cover $50.1 \%$ males and $49.9 \%$ females to maintain the national level of sex ratio in the sample. The respondents were interviewed when they were visiting some diagnostic centres in urban and semi-urban areas. The percentage of diabetic respondents included in the sample was $67 \%$ and $25.5 \%$ of them were suffering for 10 years and above, $6.4 \%$ were disable against $4.8 \%$ total disable respondents in the sample, and obese adults were $30.2 \%$. Diabetic disable adults in the sample were $4.3 \%$. The most responsible variable for diabetes disability was obesity followed by longer duration of diabetes, sedentary activity, smoking habit, being housewife, being married, etc. These variables were identified on the basis of risk ratio and correlation coefficients of variables and discriminant function scores. Beside these variables, rural people, Muslims, adults of ages 40 - 50 years, illiterate people had more risk of facing the problem of diabetes disability.
\end{abstract}

Keywords: diabetes; disability, risk ratio; discriminant analysis, socioeconomic variable; discriminant function score; correlation coefficient of variable with discriminant function score

\section{Introduction}

Physical disability for males and females indicates increased risk of not being able to do usual daily task; like normal walking, normal working, and maintaining physical balance without any support. Obesity and diabetes may increase the risk of disability because of complications arises in mobility conditions, in hearing capacity and in visual impairment , including cardiovascular disease (CVD) and peripheral vascular disease and peripheral neuropathy [ 1, 2, 3, 4 ]. In another study it was reported that the risk of disability might be increased $67 \%$ due to diabetes [5]. It was well documented fact that neuropathy is a common physical disorder, especially among elderly diabetic patients $[1,6]$. The diabetic disable patients is expected to be increased by 2025 in developed countries as older people will comprise two-thirds of the diabetic patients in those countries [ 7,8 ]. The prevalence of diabetes in adults is predicted to rise to 642 million in 2040 [9]. Currently the figure is 422 million worldwide and they are mostly from low-and middle income countries [10]. It was reported that disability prevailed among $90 \%$ of the diabetic patients in Bangladesh [11]. The rate of prevalence of the problem was $4.3 \%$ in 2006 in India compared to 1 to 2 per cent in western world [12]. Due to the prevalence of disability the chance of sleep apnea, lower limb amputation, morbidity is increased and it creates a great economic burden [12 - 19]. The problem is predominant among females, older people and diabetic patients suffering for longer duration [20, 21]. As disability increases with the increase in prevalence of diabetes, some influencing factors of diabetes viz. old age, female, illiteracy, physical inactivity, lifestyle, sedentary activity, food habit, family history etc. May be the causes of disability [5, 22-26] Keeping this health problem of adults in mind the objective of this paper was determined to identify the socioeconomic variables responsible for simultaneous prevalence of diabetes disability among Bangladeshi adults.

\section{Methodology}

The data for this paper were recorded on investigation by some nurses and medical assistants working in some purposively pre-selected diagnostic centres located in urban and semi-urban areas of Bangladesh. The investigating units were 995 adults of age 18 years and above by quota sampling plan to cover males and females in the ratio 50.1: 49.9 as this ratio is prevailed in the national level of population of Bangladesh [27]. Out of 995 respondents 498 were males and 497 were females and they were the residents of both urban and rural localities. As the adults were investigated from diagnostic centre, most $(67 \%)$ of them were found diabetic patients. The data were recorded during the session 2018-19.

The information of different socioeconomic variables of each selected respondent were recorded through a pre-designed and pre-tested questionnaire which contains different questions related to residence, 
religion, gender, marital status, age, education, occupation, family income, family expenditure. Beside these personal data, other information were on life-style, and prevalence of any of the non-communicable diseases, duration of diabetes, and the stages of treatment of the disease including its cost. Some of the variables were qualitative and some were quantitative in nature, but all the variables were noted in nominal scale for ease of analysis. The data of weight ( in $\mathrm{kg}$ ) divided by height ( in metre $^{2}$ ) was used to measure the value of body mass index (BMI) to identify obese adults( if $\mathrm{BMI} \geq 27.5$; underweight ,if $\mathrm{BMI}<18.5$; normal, if $18.5 \leq \mathrm{BMI}<23.0$; overweight, if $23.0<\mathrm{BMI}<27.5$ ) $[28,29]$. They were also divided into 4 groups According to their blood pressure (B.P) level (mmHg). The 4 groups were identified as optimal (if BP < 120/80), normal (if BP <130/85), high normal (if BP < 140/90) and hypertensive (if $\mathrm{BP} \geq 140 / 90$ ) $[30,31]$. To fulfil the objective of the study, the association of each of the socioeconomic variable with simultaneous prevalence of diabetes disability was investigated, where significant association was decided on the basis Of p-value of any $\chi^{2} \leq 0.05$.
Irrespective of significant or insignificant association, the risk ratio and its confidence interval was calculated for adults for whom prevalence of diabetes disability was noted in higher rate for a particular level of a socioeconomic variable. Finally, discriminant analysis was done to discriminate the adults suffering from diabetes disability and others who were free of these health problem. In performing discriminant analysis some of the socioeconomic variables were identified as responsible for discrimination of two groups of adults. It was done by the higher absolute values of correlation coefficients with discriminant function score and variable values $[32,33,34]$. All the calculations were done using SPSS Version 25.

\section{Result}

In the sample there were $43(4.3 \%)$ diabetic-disable adults and the remaining 952 adults were free of these two simultaneous health problems. Total respondents were classified by the prevalence of health problems and prevalence of diabetes and the classified results

\begin{tabular}{|c|c|c|c|}
\hline \multirow{2}{*}{$\begin{array}{l}\text { Prevalence of health } \\
\text { problem }\end{array}$} & \multicolumn{2}{|c|}{$\begin{array}{ll}\begin{array}{l}\text { Prevalence } \\
\text { diabetes }\end{array} & \text { of }\end{array}$} & \multirow[t]{2}{*}{ Total } \\
\hline & Yes & No & \\
\hline $\begin{array}{cc}\text { None } & \text { Number } \\
\%\end{array}$ & $\begin{array}{l}360 \\
54.0\end{array}$ & $\begin{array}{c}246 \\
75.0\end{array}$ & $606 \quad 60.9$ \\
\hline $\begin{array}{rr}\text { Heart } & \text { Number } \\
& \% \\
\end{array}$ & $\begin{array}{l}101 \\
15.0\end{array}$ & $\begin{array}{l}25 \\
7.6 \\
\end{array}$ & 12612.7 \\
\hline $\begin{array}{cc}\text { Eye } & \text { Number } \\
\%\end{array}$ & $\begin{array}{l}86 \\
12.9\end{array}$ & $\begin{array}{l}37 \\
11.3\end{array}$ & 12312.4 \\
\hline $\begin{array}{cc}\text { Kidney } & \text { Number } \\
\%\end{array}$ & $\begin{array}{l}77 \\
11.5 \\
\end{array}$ & $\begin{array}{l}15 \\
4.6 \\
\end{array}$ & $\begin{array}{l}92 \\
9.2\end{array}$ \\
\hline $\begin{array}{c}\text { Disability Number } \\
\%\end{array}$ & $\begin{array}{l}43 \\
6.4 \\
\end{array}$ & $\begin{array}{l}5 \\
1.5 \\
\end{array}$ & $\begin{array}{l}48 \\
4.8\end{array}$ \\
\hline $\begin{array}{c}\text { Number } \\
\%\end{array}$ & $\begin{array}{l}667 \\
67.0\end{array}$ & $\begin{array}{l}328 \\
33.0\end{array}$ & $\begin{array}{l}995 \\
100.0\end{array}$ \\
\hline
\end{tabular}

Table 1: Distribution of adults according to Prevalence of diabetes and health Problem

Were presented in Table 1. Total diabetic adults were 667 (67\%) and 6.4\% of them were disable also. Prevalence of diabetes and prevalence of health problem were significantly associated $\left[\chi^{2}=48.844, \mathrm{p}-\right.$ value $=0.000]$. The rural respondents were $53.4 \%$ and $4.9 \%$ of them were diabetic disable [Table 2]. For them the risk of this health hazard was $34 \%$ more compared to the risk of urban residents [R.R. $=1.34$, C.I $\{0.737$, $2.436\}]$. But prevalence rate did not vary significantly with the variation of residents [ $\chi^{2}=0.910, \mathrm{p}$-value $=0.340$; Table 2]. There were $85.2 \%$ Muslim adults and prevalence of diabetic disability was noted among $4.6 \%$ of them. The chance of this health problem for them was $69 \%$ more as it was for non-Muslim adults [R.R. $=1.69$, C.I. $\{0.613,4.656\}]$. The prevalence rates for both religious groups were statistically similar $\left[\chi^{2}\right.$ $=1.069$, p-value $=0.301]$. There were $49.9 \%$ females in the sample and $5.0 \%$ of them were suffering from diabetes and disability simultaneously. The risk of prevalence of the problem was $39 \%$ more as it was for males [R.R. $=1.39$, C.I. $\{0.768,2.517\}]$. However, there was no significant variation in the prevalence rates for males and females [ $\chi^{2}=1.206, \mathrm{p}-$ value $=0.272]$. It was observed that all 43 diabetic disable adults were currently married though marital status was not significantly associated with prevalence of this health hazard [ $\chi^{2}=3.349$, p-value=0.067]. It was noted that younger adults (age $<25$ years) were about one-fifth $(19.7 \%)$ of the respondents and prevalence of the disease was least among them.
The next lowest prevalence rate $(3.8 \%)$ was observed among $8 \%$ sample elderly adults (Age 60 years and above). Adults of ages $40-50$ years were $20.4 \%$. Among them the prevalence rate was highest $(5.9 \%)$. For them the risk of prevalence was $51 \%$ more as it was among adults of other ages $[$ R.R. $=1.51$, C.I. $\{0.789,2.889\}]$. But, statistically the prevalence rates for adults of all age groups were similar $\left[\chi^{2}=2.817\right.$, p-value $=$ 0.583 ]. There were only $6.5 \%$ illiterate adults and $7.7 \%$ of them were suffering from diabetes disability. For them the chance of prevalence of the problem was 1.88 times as it was for other educated persons [R.R. = 1.88 , C.I. $\{0.766,4.613\}]$, though prevalence rates of this health hazard were statistically similar for respondents of all levels of education [ $\chi^{2}$ $=1.928$, p-value $=0.588$ ] Higher percentage $(7.0 \%)$ of diabetes disability was observed among housewives $(23.1 \%)$. For them the risk of prevalence of the problem was $97 \%$ more as it was for other professionals [R.R. $=1.97$, C.I. $\{0.836,4.639\}]$. The next higher prevalence rate $(4.9 \%)$ was observed among retired persons $(12.3 \%)$. But, prevalence rates of diabetes disability among respondents of different occupations were statistically similar [ $\chi^{2}=0.5 .865, \mathrm{p}-$ value $\left.=0.209\right]$. Physical inactivity was observed among $51.7 \%$ adults, but rate of diabetic disability among them was lower. Higher prevalence rate $(5.0 \%)$ was observed among physically active adults. For them the risk of prevalence was $35 \%$ more as it was in others [R.R. $=1.35$, C.I. $\{0.750,1.432\}]$. However, physical labour was not significantly associated with prevalence of diabetes 
disability [ $\chi^{2}=1.005, \mathrm{p}-$ value $=0.316$ ]. The percentage of adults involved in sedentary activity was 44.2 and $6.3 \%$ of them were facing the problem of diabetes disability. The chance of prevalence of the problem for them was 2.34 times as it was for their counterpart [R.R. $=2.34$, C.I. $\{1.265,4.330\}]$. The utilization of time by the respondents and prevalence of the problem among them were significantly associated $\left[\chi^{2}=7.796, \mathrm{p}\right.$ - value $=0.000]$. The percentage of adults of families having family income
Taka 100 thousand and above was 18.7 and prevalence of diabetes disability was observed among $4.8 \%$ of them. The risk of the problem was almost similar for adults of families of other income levels [R.R. $=1.15$, C.I. $\{0.565,2.343\}]$. The prevalence rates were also statistically similar for all groups of adults of different levels of income [ $\chi^{2}=0.476, p-$ value $=0.924]$. Similar was the case for adults of families of different levels of family expenditure

\begin{tabular}{|c|c|c|c|c|c|c|}
\hline \multirow{3}{*}{ Socioeconomic characteristics } & \multicolumn{4}{|c|}{ Prevalence of diabetes disability } & \multirow{2}{*}{\multicolumn{2}{|c|}{ Total }} \\
\hline & \multicolumn{2}{|c|}{ Yes } & \multicolumn{2}{|l|}{ No } & & \\
\hline & Number & $\%$ & Number & $\%$ & Number & $\%$ \\
\hline \multicolumn{7}{|l|}{ Residence } \\
\hline Rural & 26 & 4.9 & 505 & 95.1 & 531 & 53.4 \\
\hline Urban & 17 & 3.7 & 447 & 96.3 & 464 & 46.6 \\
\hline Total & 43 & 4.3 & 952 & 95.7 & 995 & 100.0 \\
\hline \multicolumn{7}{|l|}{ Gender } \\
\hline Male & 18 & 3.6 & 480 & 96.4 & 498 & 50.1 \\
\hline Female & 25 & 5.0 & 472 & 95.0 & 497 & 49.9 \\
\hline \multicolumn{7}{|l|}{ Religion } \\
\hline Muslim & 39 & 4.6 & 809 & 95.4 & 848 & 85.2 \\
\hline Non-Muslim & 4 & 2.7 & 143 & 97.3 & 147 & 14.8 \\
\hline \multicolumn{7}{|l|}{ Marital status } \\
\hline Currently married & 43 & 4.6 & 883 & 95.4 & 926 & 93.1 \\
\hline Currently single & 0 & 0.0 & 69 & 100.0 & 69 & 6.9 \\
\hline \multicolumn{7}{|l|}{ Age (in years) } \\
\hline$<25$ & 5 & 2.6 & 191 & 97.4 & 196 & 19.7 \\
\hline $25-40$ & 18 & 4.5 & 483 & 95.5 & 401 & 40.3 \\
\hline $40-50$ & 12 & 5.9 & 191 & 94.1 & 203 & 20.4 \\
\hline $50-60$ & 5 & 4.3 & 110 & 95.7 & 115 & 11.6 \\
\hline $60^{+}$ & 3 & 3.8 & 77 & 96.2 & 80 & 8.0 \\
\hline \multicolumn{7}{|l|}{ Education } \\
\hline Illiterate & 5 & 7.7 & 60 & 92.3 & 65 & 6.5 \\
\hline Primary & 5 & 4.1 & 116 & 95.9 & 121 & 12.2 \\
\hline Secondary & 10 & 4.2 & 227 & 95.8 & 237 & 23.8 \\
\hline Higher & 23 & 4.0 & 549 & 96.0 & 572 & 57.5 \\
\hline \multicolumn{7}{|l|}{ Occupation } \\
\hline Agriculture and unemployed & 3 & 2.9 & 101 & 97.1 & 104 & 10.5 \\
\hline Business & 7 & 3.0 & 227 & 97.0 & 234 & 23.5 \\
\hline Service and skilled labor & 11 & 3.6 & 294 & 96.4 & 305 & 30.7 \\
\hline Retire & 6 & 4.9 & 116 & 95.1 & 122 & 12.3 \\
\hline Housewife & 16 & 7.0 & 93.0 & 93.0 & 230 & 23.1 \\
\hline \multicolumn{7}{|l|}{ Income ( 000 taka ) } \\
\hline$<50$ & 18 & 4.6 & 371 & 95.4 & 389 & 39.1 \\
\hline $50-100$ & 16 & 3.8 & 404 & 96.2 & 420 & 42.2 \\
\hline $100-150$ & 3 & 4.9 & 58 & 95.1 & 61 & 6.1 \\
\hline $150^{+}$ & 6 & 4.8 & 119 & 95.2 & 125 & 12.6 \\
\hline \multicolumn{7}{|l|}{ Family expenditure ( in 000 taka) } \\
\hline$<40$ & 21 & 5.0 & 395 & 95.0 & 416 & 41.4 \\
\hline $40-60$ & 10 & 3.3 & 292 & 96.7 & 302 & 30.4 \\
\hline $60-80$ & 6 & 4.2 & 137 & 95.8 & 143 & 14.4 \\
\hline $80^{+}$ & 6 & 4.5 & 128 & 94.5 & 134 & 13.5 \\
\hline Obesity & Number & $\%$ & Number & $\%$ & Number & $\%$ \\
\hline Underweight & 0 & 0.0 & 38 & 100.0 & 38 & 3.8 \\
\hline Normal & 4 & 1.7 & 229 & 98.3 & 233 & 23.4 \\
\hline Overweight & 12 & 2.6 & 412 & 97.4 & 424 & 42.6 \\
\hline Obese & 27 & 9.0 & 273 & 91.0 & 300 & 30.2 \\
\hline \multicolumn{7}{|l|}{ Smoking habit } \\
\hline Yes & 7 & 2.1 & 322 & 99.9 & 329 & 33.1 \\
\hline No & 36 & 5.4 & 630 & 95.6 & 666 & 66.9 \\
\hline Habit of taking process food & & & & & & \\
\hline
\end{tabular}




\begin{tabular}{|c|c|c|c|c|c|c|}
\hline Yes & 15 & 4.1 & 348 & 95.9 & 363 & 36.5 \\
\hline No & 28 & 4.4 & 604 & 95.6 & 632 & 63.5 \\
\hline \multicolumn{7}{|l|}{ Physical work } \\
\hline Yes & 24 & 5.0 & 457 & 95.0 & 481 & 48.3 \\
\hline No & 19 & 3.7 & 495 & 96.3 & 514 & 51.7 \\
\hline \multicolumn{7}{|c|}{ Involved in sedentary activity } \\
\hline Yes & 28 & 6.3 & 414 & 93.7 & 442 & 44.4 \\
\hline No & 15 & 2.7 & 538 & 97.3 & 553 & 55.6 \\
\hline \multicolumn{7}{|c|}{ Level of blood pressure } \\
\hline Optimum & 19 & 3.5 & 521 & 96.5 & 540 & 54.3 \\
\hline Normal & 16 & 5.7 & 264 & 94.3 & 280 & 28.1 \\
\hline High normal & 6 & 5.2 & 110 & 94.8 & 116 & 11.7 \\
\hline Hypertensive & 2 & 3.4 & 57 & 96.6 & 59 & 5.9 \\
\hline \multicolumn{7}{|c|}{ Duration of diabetes ( in years) } \\
\hline Does not arise & 0 & 0.0 & 328 & 100.0 & 328 & 33.0 \\
\hline$<5$ & 14 & 4.8 & 277 & 95.2 & 291 & 29.2 \\
\hline $5-10$ & 16 & 7.8 & 190 & 92.2 & 206 & 20.7 \\
\hline $10-15$ & 11 & 11.1 & 88 & 88.9 & 99 & 9.9 \\
\hline $15^{+}$ & 2 & 2.8 & 69 & 97.2 & 71 & 7.1 \\
\hline Total & 43 & 4.3 & 952 & 95.7 & 995 & 100.0 \\
\hline
\end{tabular}

Table 2: Distribution of adults according to socioeconomic characteristics and prevalence of Diabetes disability

[ $\chi^{2}=1.290, \mathrm{p}-$ value $\left.=0.732\right]$. However, adults belonged to families spending lowest amount of money were in $33 \%$ more risk than the risk of other adults [R.R. $=1.33$, C.I. $\{0.792,2.385\}]$. The percentage of respondents habituated in process food was 36.5 , but lower proportion (0.041) of them were patients of diabetes disability. The problem was predominant among them who were not habituated in process food. However, the risk of the problem was almost similar for process food consumers and non-consumers [R.R. $=1.07$, C.I. $\{0.574,1.976\}]$. The prevalence of this health hazard was independent of food habit of the adults $\left[\chi^{2}=0.050, \mathrm{p}\right.$-value=0.824]. But smoking habit of the respondents was not independent of prevalence of the disease $\left[\chi^{2}=\right.$ 5.772, p -value $=0.017]$. Non-smokers $(66.9 \%)$ were at the risk of prevalence of the disease by 2.54 times [R.R. $=2.54$, C.I. $\{1.142,5,651]$. The proportion of non-smokers facing the problem was 0.054 .

The percentage of adults of normal blood pressure was 28.1 and $5.7 \%$ of them were patients of diabetes disability. For them the risk of prevalence of the disease was $51 \%$ more as it was for adults of other blood pressure [R.R. $=1.51$, C.I. $\{0.826,2.762\}]$. However, prevalence rates of diabetes disability among adults of different blood pressure were statistically similar [ $\chi^{2}=2.483, \mathrm{p}$-value $=0.478$ ]. There were $30.2 \%$ obese adults in the sample and $9.0 \%$ of them were suffering from diabetes disability. The risk of prevalence of the disease for obese adults was 3.91 times as it was for others $[$ R.R. $=3.91$, C.I. $\{2.138,7.151\}]$. The Prevalence of diabetes disability was significantly different for adults of different levels of obesity $\left[\chi^{2}=23.701, \mathrm{p}-\right.$ value $\left.=0.000\right]$. There were $9.9 \%$ adults who were suffering from diabetes for 10 to less than 15 years and $11.1 \%$ of them were also suffering from disability. For this group of adults the risk of prevalence of both the diseases was 3.11 times as it was for others [R.R. $=3.11$, C.I. $\{1.619,5.978\}]$. The prevalence of diabetes disability was significantly associated with duration of diabetes $\left[\chi^{2}=32.406, \mathrm{p}-\right.$ value $=0.000]$.

\section{Discriminant Analysis}

It was observed that some of the socioeconomic variables were significantly associated with the prevalence of diabetes disability. But none was identified as most responsible one for this prevalence. The responsible variable was identified in performing discriminant analysis. The variables included in the analysis were residence, religion, gender, age, marital status, education, occupation, family income, family expenditure, Body mass index, smoking habit, consumption of process food, physical labour, utilization of time, blood pressure level and duration of diabetes. Some of these variables were significantly different for two groups of adults. These variables were significantly sufficient in discriminating the diabetic disable adults from others $[=0.943,=58.226$, $\mathrm{p}-$ value $=0.000]]$. The results of the discriminant analysis were presented in Table 3 . The analysis showed that the variable body mass index was most responsible one for discrimination followed by duration of diabetes, utilization of time, smoking habit, occupation, marital status, level of blood pressure, etc. 


\begin{tabular}{|c|c|c|c|c|c|}
\hline Variables & $\Lambda$ & $\begin{array}{l}\text { F- } \\
\text { Statistic }\end{array}$ & p-value & $\begin{array}{l}\text { Discriminant } \\
\text { coefficient }\end{array}$ & $\begin{array}{l}\text { Correlation coefficient of } \\
\text { variable and discriminant } \\
\text { function score, } r\end{array}$ \\
\hline Residence & 0.999 & 0.909 & 0.341 & -0.094 & -0.123 \\
\hline Religion & 0.999 & 1.068 & 0.302 & -0.154 & -0.133 \\
\hline Gender & 0.999 & 1.205 & 0.273 & -0.165 & 0.141 \\
\hline Marital status & 0.997 & 3.353 & 0.067 & -0.202 & -0.235 \\
\hline Age & 0.998 & 1.551 & 0.213 & -0.047 & 0.160 \\
\hline Education & 0.999 & 0.981 & 0.322 & -0.091 & -0.127 \\
\hline Occupation & 0.995 & 5.210 & 0.023 & 0.142 & 0.294 \\
\hline Family income & 1.000 & 0.004 & 0.947 & 0.033 & -0.009 \\
\hline Family expenditure & 1.000 & 0.044 & 0.834 & 0.085 & -0.027 \\
\hline Body mass index & 0.970 & 30.367 & 0.000 & 0.673 & 0.709 \\
\hline Smoking habit & 0.994 & 5.743 & 0.017 & 0.470 & 0.308 \\
\hline Consumption of process food & 1.000 & 0.048 & 0.824 & -0.032 & -0.029 \\
\hline Physical labour & 0.999 & 1.004 & 0.317 & 0.270 & 0.129 \\
\hline Utilization of time & 0.992 & 7.841 & 0.005 & 0.151 & 0.360 \\
\hline Blood pressure & 0.998 & 2.113 & 0.146 & -0.038 & 0.187 \\
\hline Duration of diabetes & 0.986 & 14.514 & 0.000 & 0.3 .99 & 0.490 \\
\hline
\end{tabular}

habit

[46].

\section{Discussion}

Long-term complications of diabetes were reported in some earlier studies [4]. One of the complications is physical disability, especially among elderly adults in both developed and developing countries $[5,9,10$, and 35]. Strong association between diabetes and physical disability was reported in earlier studies [1, 6, 36, and 37]. Beside diabetes, some other clinical and socioeconomic variables were found associated with disability $[35,38,39$, and 40]. The presentation of this paper was to focus some responsible socioeconomic variables for the prevalence of diabetes disability among some Bangladeshi urban and rural adults of ages 18 years and above. For the purpose of the study the data were recorded from adults visiting some selected diagnostic centres of urban and semi-urban areas. The centres were selected purposively. The total investigated adults were 995; among them 498 were males and 497 were females. The percentages of diabetic patients and disable persons were 67.0 and 4.8, respectively in the sample. The diabetic disable patients were $43(4.3 \%)$ and 952 adults were free of these two simultaneous health hazard. These two groups of respondents were discriminated and during discrimination some variables were identified as responsible for prevalence of diabetes disability.

In the sample there were $53.4 \%$ rural adults, $85.2 \%$ Muslim adults, $49.9 \%$ females. For all of them the risk of prevalence was higher compared to the risk of their counter parts. All 43 diabetic disable adults were married. But these four demographic characteristics were independent of prevalence of diabetes disability. The other independent demographic characteristics were age, education and occupation. But adults of ages 40 -50 years were at $51 \%$ more risk compared to that of adults of other ages. The risk of prevalence of housewife was $97 \%$ more as it was in others. The prevalence was also higher among retired persons. The females and retired persons are not directly involved in physical labour and most of them are involved in sedentary activity $[41,42]$. This study did not show any significant association between physical labour and prevalence of diabetes disability. But those who were involved in sedentary activity for them the chance of prevalence was 2.34 times as it was in others. Utilization of time was significantly associated with prevalence of this health hazard. Again, physical labour was not found associated with prevalence of the disease.

Obesity and diabetes are interrelated health hazard and these are lifestyle diseases [38, 39, 42, and 43]. Again, diabetes increases the risk of disability [5]. Hence diabetes disability are expected to be related to lifestyle. Lifestyle is related to family income and family expenditure [44, 45]. Another two components of lifestyle are smoking habit and food
These study did not show any significant association between prevalence of diabetes disability and family income or family expenditure. But adults belonged to families having minimum income of Taka 100 thousand per month were at higher risk compared to others. The chance of prevalence of the disease in adults belonged to families of lowest family expenditure was $33 \%$ more as it was for others. Though smoking habit was significantly associated with prevalence of the disease, the prevalence was not higher for smokers. The risk was 2.54 times for non- smokers. Consumption of process food was independent of prevalence of diabetes disability.The risk factor for human being is level of obesity and this factor was significantly associated with prevalence of diabetes disability. The risk of the disease for obese adults was 3.91 times as it was in others. Duration of diabetes was significantly associated with prevalence of diabetes disability. The risk of the disease was 3.11 times for adults suffering from diabetes for $10-15$ years.

Finally, it was observed that the most responsible variable for diabetes disability was body mass index followed by duration of diabetes, sedentary activity, smoking habit, being female and married, etc. These were identified from the results of discriminant analysis and risk ratios.

\section{Conclusion}

The objective of the paper was to identify some responsible socioeconomic variables for the prevalence of diabetes disability among Bangladeshi adults. The adults of ages 18 years and above visiting some pre-selected diagnostic centres located in urban and semi-urban areas were interviewed by some nurses and medical assistants of the centres. During investigation males and females were covered in the ratio 50.1: 49.9 to maintain the national level of sex ratio.

The sample covered $53.4 \%$ rural and $46.6 \%$ urban respondents. Diabetes was noted among $67 \%$ of the adults and disability was observed in $6.4 \%$ of them. Total disable adults were $4.8 \%$.

Diabetes disability was predominant among females, Muslims and rural adults. All noted diabetic disable adults were found married. Adults of ages $40-50$ years were at higher risk of prevalence of this health hazard compared to the risk of others. Housewives, adults of higher income group and lowest expenditure group of families were at higher risk of prevalence of the problem. But all the above socioeconomic variables were independent of diabetes disability. Adults involved in sedentary activity were at higher risk of facing the problem of this health hazard. Obese adults had around 4 times chance of affecting by the disease. Diabetic adults suffering for $10-15$ years were at around 3 times risk of 
prevalence of the problem. Level of body mass index, smoking habit, utilization of time, and duration of diabetes were significantly associated with prevalence of diabetes disability.

The two groups of respondents were significantly different in respect of variables occupation, smoking habit, utilization of time, body mass index, and duration of diabetes. Out of these above mentioned variables, the most responsible one for discrimination of two groups of adults was body mass index followed by duration of diabetes, sedentary activity, smoking habit, occupation, etc.

Due to upward social mobility and change of lifestyle the prevalence of diabetes and its complications cannot be avoided. But impacts of diabetes and other non-communicable diseases originated from diabetes can be controlled if proper action plan is formulated and implemented the plan at national level. The health planners and rural and urban health workers can do a lot to maintain a healthy life in the society. For this, the following actions can be suggested for the people in the society.

(i) To control the body weight by doing some physical work and physical exercise so that body mass index is not increased.

(ii) To avoid restaurant food, can food, salty and fatty food as per as possible,

(iii) To join blood screening programme whenever it is possible.

(iv) To adhere the regular treatment of diabetes and hypertension.

(v) Avoid smoking and taking drugs and drinks,

\section{References}

1. Edward, W. G.; Gloria L.A, B.; David F. W.; Suzzane G. L.; Jean A. L. ; Micheal M. E. and Venkat Narayan, K.M. (2000): Diabetes and physical disability among older U.S. adults, Diabetes Care,23, 1272 - 1277.

2. Diabetes and Disability: American Association of Diabetes Education, Practice Paper,2015.

3. Centres for Disease Control and Prevention (1997): Atlanta G.A.

4. Nathan, D.M.( 1993): Lng-term complications of diabetes mellitus, N Engl JMed, 328, 1676 - 1685.

5. Tabesh, M.; Shaw, J.; Zimmet, P.Z. Stefan, S. ; Digsu, N.K. ; Sudhir, K.; Mariyam, T.; Noorjehan, J. Ameena, S.; and Gayan, P. (2018): The association between type 2 diabetes and disability: What is the contribution of diabetes risk facto and diabetes complications? Jour of diabetes,10(9), DOI:10.1111/1753-0407.12659.

6. Edward, W.G.; Carol,,M.M.; Jane, A.C. ; Theodore, J.T.; Ann, V.S.; Kristine, E.E. and Micheal, C.N. (2002); Diabetes and incidence of functional disability in older women, Diabetes Care, $25,61-67$.

7. Robinson, N. (2009); Disability and diabetes, International Disability Studies, 12, $28-31$.

8. King, H.; Aubert, R.E.; Herman, W.H. (1998): Global burden of diabetes, 1995 - 2025: Prevalence, numerical estimates and projections, Diabetes Care, 21, 518 - 524 .

9. International Diabetes Federation (IDF): Diabetes Atlas, $7^{\text {th }}$ Edition, 2015, Brussels.

10. WHO ( 2020): Newsroom/Facts in Pictures/details/Diabetes.

11. Akhter, N.(2019): Diabetic peripheral neuropathy : Epidemiology, physiopathology, diagnosis, and treatment; Review Article, Delta Med. Col. Jour., 7(1), 35 - 48.
12. Mitra, T.; Gogas, D.Y.; Abd A. Tahrani; Selvarigh, D. ; Bowling, F.L. and Hassan, F. (2017): diabetic neuropathy : current status and future prospects, Jour. Diabetes Res., Article I.D. 5825971,

13. Vinik, A.; Park, T.S.; Stansberry, K.D. and Pittenger, G.L.( 2000): Diabetic neuropathies, Diabetology, 43(8), 957 - 973.

14. Tahrani, A.A. ; Altaf,Q.A.;Piya, M.K. and Barnett, A.H. (20170: Peripheral and autonomic neuropathy in South Asian and White Caucasians with Type-2 diabetes mellitus possible explanations for epidemiological differences , Jour. Diabetes, I.D. 1273789,

15. Bansal, V.; Kabita, J. and Misra, U.K. (2006): Diabetic neuropathy, Postgraduate Medical Jour. 82(964), 95 - 100.

16. Vinik, A. and Zeigler, D.(2007): Diabetic cardiovascular automatic neuropathy, Circulation, 115(3), 387 - 397.

17. Partanen, J; Niskanen, L. Lehtinen, J.; Marvaala, F.; Siitonen, O. and Uusitupa, M.I.J.(1995): Natural history of peripheral neuropathy in patients with non-insulin dependent diabetes mellitus. New England Jour. Med. 333(2), 89 - 94.

18. Tasfaye, S.; Chauturvedi, N. ; Eaton, S.E.M.et al ( 2005): Vascular risk factors and diabetic neuropathy, New England Jour.Med.352(4), 341 - 431.

19. Tahrani, A.A. ; Ali, A.;Raymond, N.T. et al (2013): obstructive sleep apnea and diabetic neuropathy : a cohort study, Diabetes Care, 36(11), 3718 - 3725.

20. Rahman, M.M,; Rezvi, A,N.;Uddin,M.N.; Khanam, R.A. Khan, M.A.M.; Khanam, S. ( 2019): Demographic characteristics of diabetic neuropathy patients attended a tertiary care hospital in Dhaka city, Medicine Today, 31(1), 27 - 30,

21. Ashoke, S.; Rama, M.; Deepa, R. ; Mohan, V. (2002): prevalence of neuropathy in Type-2 diabetes attending a diabetic centre in South India, Jour. Assoc. Physicians, India, 50, 546 - 550.

22. Bhuiyan, D. and Bhuyan, K.C.(2019): Discriminating Bangladeshi adults by non-communicable diseases, Rehabilitation Science, 4(3), 35

23. Katherine, F.G. and Donald, F. (2011): Obesity and disability, Amer Jour Prev Med., 42(5), 541 - 545

24. Raggi, A.; Brunani, A.; Sirtori, A.; Liuzzi, A.;Berselli, M.E.; Valentilla, V.; Francesca, C. and Leonardi, M.(2010): Obesity related disability : key factors identified by the International Classification of Functioning, Disability and Heath, Jour Disability and Rehabilitation, 32,

25. Temple, V.A.; Walkley, J.W.; Greenway, K. (2010): Body mass index as an indicator of adiposity among adults with intellectual disability, Jou Intelle Dev Disability, 35(2), 116 - 120.

26. Ellis,L.J. ; Lang, R. and Shield, J.P. ( 2006): Obesity and disability - a short review, Obes Rev, 7(4), 341 - 345.

27. Bangladesh Bureau of Statistics (2018): Statistical Year Book of Bangladesh,2017, BBS, Dhaka, Bangladesh.

28. Appropriate Body Mass Index for Asian Population and its Implications for Policy and Intervention Strategies, WHO Expert Consultation, Public Health, Lancet 363, 2004.

29. Biswas, T.; Garnett, P. Sarah and Rawal, B.Lal ( 2017): The prevalence of underweight, overweight, and obesity in Bangladesh: Data from a national survey, PLoS One, 12(5), e0177395.

30. Jan, A.S. ; Yan, Li.; Azusa, H.; KEI, A.; Eamon, D. and O'Brien, E. : Blood pressure measurement anno 2016. Amer Jour Hypertens, 2017, 30(5), 453 - 463.

31. Jessica, Y.I.;Zaman, M.M.; Haq, S.A.; Ahmed, S. and AlQuadir ,Z. ( 2018): Epidemiology of hypertension among Bangladeshi adults using the 2017 ACC/AHA Hypertension Clinical Guidelines and Joint National Committee 7 Guideline, Jour Hypertens, 32, $668-680$. 
32. Bhuyan, K.C. (2019): A note on the application of discriminant analysis applied in medical research, Archives of Diabetes and Obesity, 2(2), 142 - 146, DOI:10.3244/ADO.2019.02.000132.

33. McLachlan, G.J. ( 2004): Discriminant and Statistical Pattern Recognition, Wiley Inter-science, ISBN 978-0-471-69115-0.

34. Garson, G.D. (2008): Discriminant function analysis,

35. Koye, D.N.; Shaw, J.E.; Magliano, D.J. (2017): Diabetes nd disability in older Australians: The Australian Diabetes, Obesity and Lifestyle Study, Diabetes Research, clin.Practice, 126, 600 67.

36. Evelyn, W.; Kathryn, B.; Emma, G.; Jessica,H.; Rossane, F.; Christopher, S. and Anna, P.(2013): Diabetes and risk of physical disability in adults: a systematic review and meta-analysis, The Lancet, Diabetes and Endocrinology, 1(2), 106 - 114,

37. Biswas, T.; Garnett, P. Sarah and Rawal, B.Lal ( 2017): The prevalence of underweight, overweight, and obesity in Bangladesh: Data from a national survey, PLoS One, 12(5), e017739

38. Katherine, F.G. and Donald, F. (2011): Obesity and disability, Amer Jour Prev Med., 42(5), 541 - 545

39. Raggi, A.; Brunani, A.; Sirtori, A.; Liuzzi, A.;Berselli, M.E.; Valentilla, V.; Francesca, C. and Leonardi, M.(2010): Obesity related disability : key factors identified by the International Classification of Functioning, Disability and Heath, Jour Disability and Rehabilitation, 32,
40. Temple, V.A.; Walkley, J.W.; Greenway, K. (2010): Body mass index as an indicator of adiposity among adults with intellectual disability, Jou Intelle Dev Disability, 35(2), 116 - 120.

41. Syed, M.S.; Debra, N.;Muhammad, H.R.; Musa, R; AND Gul, N.( (2004): Assessing obesity and overweight in a high mountain Pakistani population, Tropical Medicine and International Health,9(4), 526-532.

42. Bhuyan,K.C. and Fardus,J. ( 2019): Level of obesity and socioeconomic factors of a group of adult people of Bangladesh: A factor analysis approach, Amer, Jour. Data Mining and Knowledge Discovery, 4(1), 8-14, doi: 10.11648/j.ajdmkd.20190401.12.

43. Dinsa, G.D.; Goryakin, Y. ; Fumagalli, E. and Suhrcke, M.( 2012): Obesity and socioeconomic status in developing countries: A systematic review, Obesity Reviews , 13(11), 106779 ,.

44. Bansal, V.; Kabita, J. and Misra, U.K. ( 2006): Diabetic neuropathy, Postgraduate Medical Jour. 82(964),95 - 100.

45. Bhuyan, K.C.(2020): Factors responsible for obesity neuropathy among Bangladeshi adults, International Jour Res Studies Med and Health Sci., 5(19), $14-21$.

46. Bhuyan, K.C. ( 2019): Factors responsible for noncommunicable diseases among Bangladeshi adults,, Biomedical Journal of Scientific and Technical Research ( biomed J Sci \& Tech, Volume 20(2), $14742-14748$.
This work is licensed under Creative Commons Attribution 4.0 License
To Submit Your Article Click Here: Submit Manuscript

DOI: $10.31579 / 2641-8975 / 0027$
Ready to submit your research? Choose Auctores and benefit from:

$>$ fast, convenient online submission

$>$ rigorous peer review by experienced research in your field

$>$ rapid publication on acceptance

$>$ authors retain copyrights

$>$ unique DOI for all articles

$>$ immediate, unrestricted online access

At Auctores, research is always in progress.

Learn more https://auctoresonline.org/journals/diabetes-and-islet-biology 